\title{
Practices and Knowledge on the Prevention of Cervical Cancer in Elderly Women
}

\author{
Candyce Simões Malta Marques Silva, Camila Maria Beder Ribeiro, Evanio da Silva, \\ José Gildo da Silva, Euclides Maurício Trindade Filho, Kristiana Cerqueira Mousinho* \\ CESMAC University Center, Maceió, Alagoas State, Brazil \\ Email: *kristianamousinho@gmail.com
}

How to cite this paper: Silva, C.S.M.M., Ribeiro, C.M.B., da Silva, E., da Silva, J.G., Filho, E.M.T. and Mousinho, K.C. (2018) Practices and Knowledge on the Prevention of Cervical Cancer in Elderly Women. Open Journal of Epidemiology, 8, 29-42.

https://doi.org/10.4236/ojepi.2018.81003

Received: December 13, 2017

Accepted: January 28, 2018

Published: January 31, 2018

Copyright $\odot 2018$ by authors and Scientific Research Publishing Inc. This work is licensed under the Creative Commons Attribution-NonCommercial International License (CC BY-NC 4.0). http://creativecommons.org/licenses/by-nc/4.0/

\begin{abstract}
Cancer is a public health problem, primarily in developing countries. Elderly women are more prone to contracting different diseases, including sexual related neoplasms. The aim of this study was to determine the strategies used and knowledge regarding the prevention of cervical cancer in elderly women. This is a cross-sectional observational study. The sample was comprised of elderly women residents from the Brazilian Northeastern city who attended a coexistence group for elder people. After sample, calculation was obtained $\mathrm{N}$ of 209 participants. Associations between the independent and dependent variables were analyzed using the chi-squared test, considering $\mathrm{p} \leq 0.05$ as significant. The following programs were used for statistical analyses: Excel (Microsoft Office ${ }^{\circledR}$ ), to tabulate the data and prepare the tables and Bioestat ${ }^{\circledR} 5.3$ to test the associations. The prevalent age range was 60 to 70 years; most of the subjects were retired and had secondary schooling. Although a large number of those interviewed knew about cervical cancer, their knowledge was insufficient to take preventive measures. It is important that the elderly undergo a Pap smear, since the number of increasing cervical cancer cases is known to increase in this age range. In the coming decades, Brazil will have a significant elderly population, reaffirming the growing need for educational campaigns related to the health of elderly women, encouraging self-care and prevention in old age.
\end{abstract}

\section{Keywords}

Cancer, Cervical Cancer, Elderly Women

\section{Introduction}

Cancer is a serious public health problem worldwide, primarily in developing 
countries. The World Cancer Report of 2014, published by the World Health Organization (WHO), estimated that $80 \%$ of the more than 20 million new cancer cases forecast by the year 2025 will occur in developing countries with a mortality rate of 70\% [1]. In Brazil, approximately 420,000 new cases of cancer are expected to occur in 2016 and 2017, not including nonmelanoma skin cancer. The main types of cancer that will affect Brazilian women are breast, bowel, cervical, lung and stomach [2]. With respect to cervical cancer, there are approximately 530,000 new cases a year worldwide, accounting for 265,000 deaths/ year, making it the fourth leading cause of death from cancer in women [3]. Persistent infections by oncogenic subtypes of HPV (Human Papillomavirus), primarily HPV-16 and HPV-18, are closely related to the emergence of cervical cancer. Around $70 \%$ of cases are caused by these two types of viruses. Other aspects also seem to influence the still uncertain mechanisms that determine the regression or persistence of the infection and progression to precursor lesions or cervical cancer, including low immunity, genetic and sexual behavior. Thus, smoking, early sexual intercourse, multiple sexual partners and the use of oral contraception are important risk factors for the development of cervical cancer. Another important factor in the HPV infection process is the woman's age. Notably, women aged 30 years or younger exhibit a strong tendency to spontaneous regression of infections, but in women over 30 , the virus is frequently more persistent [4]. The WHO estimates that in 2020 Brazil will rank sixth in the number of cases in women aged 60 years or older. Mortality rates for cancer in the elderly are also progressively rising, making this disease the second leading cause of death in this population group, with cervical cancer ranking third in women [5]. Elderly women are more prone to developing numerous diseases, including sexual related neoplasms, which are an important cause of morbidity and determinant of mortality in seniors. Behavioral, cultural and social factors may contribute to the emergence of cervical cancer, as well as the lack of adherence to prevention routines and self-care practices that tend to be neglected or even nonexistent among elderly individuals [6]. Few studies discuss cervical cancer prevention in the elderly, creating a knowledge gap. The quality of life of women and healthy aging require better understanding of a set of factors that make up the daily routine of these seniors, using strategies which are accessible to this population. The lack of awareness in these individuals interferes directly in self-care.

Thus, the following question is raised: what preventive practices and knowledge about cervical cancer are applied by elderly women?

As such, the aim of this study is to determine the practices and knowledge of cervical cancer in elderly women.

\section{Materials and Methods}

This is a cross-sectional study approved by the institutional Research Ethics Committee, under protocol number 1.626.12.

The sample was comprised of elderly women residents from the Brazilian Northeastern city who attended a coexistence group for elder people during July 
to September of 2016. The sample size was determined in 209 women, using the equation described and defined by Triola, for a finite population composed of 652 , admitting an error of 0.05 [7].

The elderly were individually invited (verbally) to take part in the research, in a private setting. All participants gave their informed consent and the guidelines for human research were strictly adhered to.

Assessment instrument consisted of a questionnaire divided into three blocks, as follows: sociodemographic indicators, cervical cancer prevention and the practices and awareness of cervical cancer prevention adapted from Maeda quationnaire [5]. Although the instrument of data collection was not validated becoming a limitation of the study, it was constructed with adequate language and accessible to the participants.

Statistical analyses were carried out after data tabulation, where the quantitative variables were presented at intervals. The qualitative variables were described in frequency tables. In statistical inference, an association between independent and dependent variables was determined using the chi-squared test, at a significance level of $\mathrm{p} \leq 0.05$.

\section{Results}

Of the 209 elderly interviewed, all completed the questionnaire satisfactorily. Sociodemographic profile from Elderly Social Group, 2016 is summarized in Table 1.

In the second block of questions, the results are related to prevention. In the third and last block of questions, the elderly reported on what they knew about cervical cancer prevention, as Table 2 and Table 3.

With respect to associations, sociodemographic variables more closely linked to preventive measures (age range, number of children, schooling level, family income and health services) were used in conjunction with the preventive measures variables contained in the second block of questions on the questionnaire. No significant values were found in the associations between age range and undergoing the screening test, use of contraception and sexually transmitted disease. However, there was an association between age range and an active sex life in Table 4.

The association between number of children and preventive measures: an active sex life and sexually transmitted diseases was not statistically significant in Table 5. However, when the number of children was associated with undergoing the screening test and use of contraception, significance was found for both.

The variables schooling level and health services used by the elderly showed no significant $\mathrm{p}$-values in any of the associations with the sociodemographic variables analyzed. However, family income exhibited a significant p-value when associated with undergoing screening and an active sex life in Table 6.

\section{Discussion}

In Brazil, cervical cancer is one of the leading causes of female morbidity. There 
Table 1. Sociodemographic profile of the Elderly Social Group, 2016.

\begin{tabular}{|c|c|c|}
\hline Variables & $\mathrm{N}$ & $\%$ \\
\hline \multicolumn{3}{|l|}{ Age range } \\
\hline $60-70$ & 138 & 66.0 \\
\hline $71-80$ & 57 & 27.3 \\
\hline Older than 81 to 93 & 14 & 6.7 \\
\hline \multicolumn{3}{|l|}{ Number of children } \\
\hline Up to 3 & 151 & 72.2 \\
\hline 4 or more & 58 & 27.8 \\
\hline \multicolumn{3}{|l|}{ Alcoholic beverages } \\
\hline Yes & 122 & 58.4 \\
\hline No & 87 & 41.6 \\
\hline \multicolumn{3}{|l|}{ Drinking frequency } \\
\hline Daily & 0 & 0.0 \\
\hline Weekly & 10 & 8.2 \\
\hline Socially & 92 & 75.4 \\
\hline \multicolumn{3}{|c|}{ Use of oral contraception } \\
\hline Yes & 81 & 38.8 \\
\hline No & 128 & 61.2 \\
\hline \multicolumn{3}{|c|}{ Duration of oral contraception } \\
\hline 1 to 3 years & 18 & 22.2 \\
\hline 4 to 6 years & 13 & 16.1 \\
\hline 7 to 9 years & 20 & 24.7 \\
\hline 10 or more years & 30 & 37.0 \\
\hline Total & 209 & 100.0 \\
\hline
\end{tabular}

Source: Research data.

Table 2. Factors related to cervical cancer prevention.

\begin{tabular}{lcc}
\hline \multicolumn{1}{c}{ Variables } & $\mathrm{N}$ & $\%$ \\
\hline 1) Have you undergone cervical cancer screening? & 171 & 81.8 \\
Yes. & 35 & 16.7 \\
No & 03 & 1.4 \\
I do not remember. & 00 & 0.0 \\
I decline to answer & & \\
2) If yes, how long ago? & 63 & 36.8 \\
In the last year. & 13 & 7.6 \\
More than 1 year ago. & 20 & 11.7 \\
More than 2 years ago. & 45 & 26.3 \\
3 or more years ago. & & \\
\hline
\end{tabular}




\section{Continued}

I do not remember.

30

I decline to answer.

3) If no, why did you not undergo the examination?

Fear.

Embarrassment.

Inconvenience.

Beyond the age that requires testing.

Others.

I decline to answer.
$00 \quad 0.0$

$\begin{array}{ll}01 & 2.8 \\ 07 & 20.0 \\ 05 & 14.3 \\ 13 & 37.1 \\ 06 & 17.1 \\ 03 & 8.7\end{array}$

4) Do you have an active sex life?

Yes.

$83 \quad 39.7$

No.

$126 \quad 60.3$

I decline to answer.

$00 \quad 0.0$

5) If yes, do you use male or female contraception?

Yes.

$23 \quad 27.7$

No.

$60 \quad 72.3$

I decline to answer.

00

6) How many sexual partners have you had?

None.

$04 \quad 1.9$

1 partner.

$79 \quad 37.8$

2 to 4 partners.

$88 \quad 42.1$

5 or more partners.

$35 \quad 16.7$

I decline to answer.

$03 \quad 1.4$

7) Have you had an STD (sexually transmitted disease)?

Yes.

$36 \quad 17.2$

No.

$171 \quad 81.8$

I decline to answer.

$03 \quad 1.0$

8) If yes, which?

HPV.

$19 \quad 52.8$

Syphilis.

$07 \quad 19.4$

Hepatitis B.

$07 \quad 19.4$

Others.

$01 \quad 2.8$

I decline to answer.

$02 \quad 5.5$

Total 100.0

Source: Research data. 
Table 3. Knowledge of cervical cancer prevention.

\begin{tabular}{lcc}
\hline \multicolumn{1}{c}{ Variables } & $\mathrm{N}$ & $\%$ \\
\hline 1) Do you know what cervical cancer is? & & \\
Yes. & 175 & $\mathbf{8 3 . 7}$ \\
No. & 34 & 16.3 \\
I decline to answer. & 00 & 0.0 \\
2) Do you know how to prevent it? & 136 & $\mathbf{6 5 . 1}$ \\
Yes. & 39 & 18.7 \\
No. & 00 & 0.0
\end{tabular}

3) Do you know what the Pap test or oncotic cytology is?

Yes.

No.

I decline to answer.

4) Who informed you about the cervical cancer prevention test?

Health professionals.

Family members.

Cancer prevention campaigns.

Others.

5 Who encouraged you to undergo cervical cancer screening?

Health professionals.

Family members.

Cancer prevention campaigns.

Others.

6) Do you know the risk factors for cervical cancer?

Yes.

No.

I decline to answer.

7) If yes, which one or ones?

Only 1 risk factor.

2 to 4 risk factors.

5 or more risk factors.

8) Do you know what HPV is?

Yes.

No.

I decline to answer.

$01 \quad 0.5$

9) Would you like to receive information, lectures and workshops about cervical cancer prevention?

Yes.

No.

I decline to answer.

10) If yes, how?

Only 1 alternative.

2 to 4 alternatives.

Total

Source: Research data.
$188 \quad 90.0$

$21 \quad 10.0$

$00 \quad 0.0$

$17 \quad 62.3$

$71 \quad 37.7$

$209 \quad 100.0$ 
Table 4. Association between age range and an active sex life.

\begin{tabular}{cccccccc}
\hline & \multicolumn{5}{c}{ Age range } & \\
\cline { 2 - 6 } Variable & \multicolumn{6}{c}{$60-70$ years } & \multicolumn{2}{c}{$71-80$ years } & \multicolumn{2}{c}{$>81$ years } & p-value* \\
\cline { 2 - 6 } & $\mathrm{N}$ & $\%$ & $\mathrm{~N}$ & $\%$ & $\mathrm{~N}$ & $\%$ & \\
\hline Sexually active & & & & & & & \multirow{2}{*}{0.0001} \\
Yes & 77 & 6,8 & 06 & 2,8 & 00 & 00 & \\
No & 61 & 29.1 & 51 & 24.4 & 14 & 6.6 & \\
\hline
\end{tabular}

${ }^{*}$ Chi-squared test.

Table 5. Associations between number of children and preventive measures.

\begin{tabular}{cccccc}
\hline \multirow{2}{*}{ Variable } & \multicolumn{5}{c}{ Number of children } \\
\cline { 2 - 6 } & \multicolumn{4}{c}{ Up to 3 children } & \multicolumn{2}{c}{4 or more children } & p-value $^{*}$ \\
\hline Underwent screening & $\mathrm{N}$ & $\%$ & $\mathrm{~N}$ & $\%$ & \\
Yes & 130 & $\mathbf{6 2 . 2}$ & 41 & $\mathbf{1 9 . 6}$ & $\mathbf{0 . 0 3}$ \\
No & 20 & 9.5 & 15 & 7.1 & \\
Use of contraception & & & & & \\
Yes & 39 & $\mathbf{1 8 . 6}$ & 47 & $\mathbf{2 2 . 4}$ & $\mathbf{0 . 0 1}$ \\
No & 30 & 14.8 & 43 & 20.5 & \\
\hline
\end{tabular}

${ }^{\star}$ Chi-squared test.

Table 6. Associations between family income and preventive measures.

\begin{tabular}{|c|c|c|c|c|c|c|c|}
\hline \multirow{3}{*}{$\begin{array}{c}\text { Variable } \\
\text { Underwent screening }\end{array}$} & \multicolumn{6}{|c|}{ Family income } & \multirow{3}{*}{ p-value ${ }^{*}$} \\
\hline & \multicolumn{2}{|c|}{$\begin{array}{l}\text { Up to } 1 \text { minimum } \\
\text { monthly wage }\end{array}$} & \multicolumn{2}{|c|}{$\begin{array}{l}2-3 \text { minimum } \\
\text { monthly wages }\end{array}$} & \multicolumn{2}{|c|}{$\begin{array}{l}4 \text { or more minimum } \\
\text { monthly wages }\end{array}$} & \\
\hline & $\mathrm{N}$ & $\%$ & $\mathrm{~N}$ & $\%$ & $\mathrm{~N}$ & $\%$ & \\
\hline Yes & 26 & 12.4 & 142 & 67.9 & 3 & 1.4 & 0.0001 \\
\hline No & 7 & 3.3 & 14 & 6.6 & 14 & 6.6 & \\
\hline \multicolumn{8}{|l|}{ Active sex life } \\
\hline Yes & 14 & 6.6 & 25 & 11.9 & 44 & 21 & 0.008 \\
\hline No & 20 & 9.5 & 62 & 29.6 & 41 & 19.6 & \\
\hline
\end{tabular}

${ }^{\star}$ Chi-squared test.

are a number of challenges that need to be addressed in the search to widen prevention programs, in order to promote early detection of this disease. The sociodemographic profile found in this study resembles those of similar investigations in terms of the risk factors for cervical cancer and the predicted aging of the population with an active lifestyle. In biological terms, aging is only one stage of the life cycle, in which the natural decline of organic structures is most evident. However, the aging process is much more complex, and not confined merely to biological concepts, involving social, cultural and subjective issues. Studies that analyzed cervical cancer in the same age range found a higher num- 
ber of women aged between 60 and 69 years and widowed, obtaining similar results to those reported here [8]. In relation to the number of children, studies corroborate these study findings that most seniors had up to three children, multiparity being an important risk factor in the increased incidence of cervical cancer. In regard to the use of alcoholic beverages, none of the studies show it as a risk factor for developing the disease, but there is a relation between the use of alcohol and not undergoing preventive screening. Prolonged use of contraception is widely reported in the literature as an important risk factor in the incidence of cervical cancer among elderly women. There are two types of contraceptives, namely, those composed of estrogen and progesterone and those composed only of progesterone. The most recommended are those with the lowest amount of hormones, since this is closely associated with cervical cancer. The risk is even greater in women with HPV who use contraception: the longer the use the greater the risk. In relation to smoking, there were a significant number of non-smokers, defined as women who had quit smoking, regardless of the time since they gave up the habit. Studies show that the main causes of death in the female population are cardiovascular diseases (acute myocardial infarction and stroke), followed by malignant neoplasms (breast, lung and cervical) and respiratory diseases. The three primary causes may be related to smoking [9]. One study identifies the oncogenic substances present in tobacco, such as nicotine and cotinine, as the reason smoking is a risk factor for developing cervical cancer [10]. Inhaled cigarette smoke goes directly to the lungs and is then distributed the circulatory system, where nicotine reaches the brain in 7 to 19 seconds. Thus, the substances contained in tobacco spread throughout the body at a speed similar to that of intravenous injection. Nicotine addiction is related to around 50 pathologies, including a number of cancers (lung, laryngeal, pharyngeal, esophageal, stomach, pancreatic, liver, kidney, bladder, cervical and leukemia). With respect to employment, literature studies show that the vast majority of seniors are retired, corroborating the findings of this investigation. In regard to education level, most of the subjects had secondary schooling, followed closely by university level. In a similar study that analyzed seniors ' knowledge of the Pap test, most of the elderly had three to five years of schooling and scant knowledge of the screening test [11]. When compared with the data obtained here, the elderly had more schooling, that is, secondary education (39.2\%), which may have contributed to their better understanding of cervical cancer prevention. The values found for house ownership were significant and compatible with the fact that most had a family income of 4 or more minimum monthly wages ( $\geq$ USD1200.00). Other studies have shown that low family income may be a risk factor for the emergence of diseases, given that poor living conditions cause individuals to neglect their health [12]. In this study most of the elderly subjects did not live alone, an important factor for health care. This corroborates literature findings, in which most seniors live with friends or family members as opposed to their partners, since this age group requires greater care 
[13]. The most commonly used health service was insurance plans, which may facilitate access to clinical and laboratory screening tests for cervical cancer. However, studies show that most seniors use the National Health System (SUS) [14]. Although the Pap test is a simple, easy and inexpensive procedure, the elderly that rely on the SUS still face difficulties accessing the test and long waiting periods. This may explain the lack of adherence to preventive measures and represents an aggravating factor in the screening of cervical cancer [15]. Quality cancer control programs with comprehensive coverage and follow-up of women with cervical lesions could reduce the incidence of cervical cancer by around $80 \%$ [16]. With respect to elderly women having undergone cervical cancer screening, most responded that they had submitted to the test the previous year, followed by 3 or more years. There are few literature studies on cervical cancer prevention in the elderly. Studies in different regions of Minas Gerais State obtained conflicting results in terms of cancer screening. In southeastern region, studies showed that a majority of the elderly interviewed (84.12\%) had undergone cervical cancer screening, while another investigation in the north of the state found that $56.3 \%$ of seniors had never been tested. This difference in studies shows that undergoing screening or not varies substantially between the regions investigated. In relation to the reasons given by the elderly for not undergoing the cancer prevention test, the most common response was that they were beyond the age of screening, followed by feeling embarrassed. Lack of information on the importance of screening is the primary factor and may contribute negatively to not undergoing the prevention test. In Brazil, the cervical cancer screening criteria adopted by the Ministry of Health (MS) for women aged 65 years or older are three Pap tests in the previous 20 years with negative results or two consecutive negative tests in the last 10 years. In either of these situations, screening should be interrupted, based on the low index of positive cases after the age of 65. It is important to remember the scarcity of studies with women in this age range and the growing number of positive cases in women aged 60 years or older. Among the reasons for the difficulty in conducting studies is the physical discomfort in undergoing the test, which may lead to unsatisfactory or falsepositive results. In regard to an active sex life, most reported not engaging in regular sexual activity, which may be associated with not living with partners or being widows. Studies report that elderly individuals continue to have an active sex life in old age, but changes that occur in both men and women may compromise sexual pleasure. To avoid poor affective relationships, individuals must adapt to these changes [17]. There is still a strong prejudice about sexuality in the elderly, whereby that society continues to consider it inadequate or abnormal behavior [18]. Of the elderly that reported having an active sex life, most did not use contraception during sexual relations. Studies reveal that not using contraception may be associated with the fact that women believed that they were protected, since they were in a stable relationship, or not at risk of contracting HPV [19]. With respect to the minority that uses contraception, studies demonstrate 
that women think that screening is unnecessary, since they are protected during sexual intercourse [20]. There was significant similarity in the number of partners during the life of elderly individuals, that is, most had 2 to 4 partners, in line with the majority of published studies, showing multiple partners as an important risk factor for contracting sexually transmitted diseases (STDs), compared with women who had only one partner. The dearth of studies on cervical cancer prevention in the elderly demonstrates the need to intensify screening campaigns in this age group, even limiting daily risk factors such as decreasing the frequency of sexual relations and the number of partners. In the responses regarding contamination by STDs, only a small percentage reported their occurrence. Still considering the variable STD, in the present study another limitation was observed since in the instrument of data collection in the category of "OTHER STDs" it was necessary the verbal description of what could be these diseases for the question to be adequately answered. Literature studies confirm that gradual population aging in Brazil, increased life expectancy and the rising number of seniors make them more vulnerable to chronic diseases. The lack of knowledge and search for information on these infections, including treatment and prevention, remain scarce in the elderly population. The rediscovery of sexual pleasure thanks to the various media access existing today make the elderly even more prone to sexually transmitted diseases (STDs), due to unsafe sexual practices. Some social groups still hold the belief that sex is solely for procreation purposes, causing prejudice, including from some health professionals, regarding the sexual behavior of elderly individuals [21]. Another important finding is that HPV infections predominated in seniors who reported having had a previous STD. The rising sexually active elderly population facilitates contact with the HPV virus, thereby increasing the likelihood of developing cervical cancer. In block 3 of the questionnaire, when asked about the factors related to cervical cancer prevention, the seniors reported being aware of the risk factors involved. Similar studies found that a majority of elderly individuals enrolled in social groups know about the disease through its occurrence in a friend or family member or for having read or heard about it. However, studies show that even though seniors declare knowing about the disease, most do not have sufficient knowledge of the pathology, as demonstrated in our research [22]. The different leisure options available in social groups for the elderly make them ideal spaces to interact, allowing members to forge new friendships and share their experiences of aging, breaking paradigms and creating new identities for social interaction. The seniors studied here conveyed joy and the desire to learn and experience life. Many reported that before joining the group, they lived with pain that precluded the common activities of daily living, but after enrolling, their lifestyle became healthier, allowing them to enjoy better quality of life. With respect to prevention, the Pap test and oncotic cytology, the seniors reported being aware of these; however, in terms of the different ways to prevent cervical cancer, the number was less than the $90 \%$ who claimed to know about the Pap test. Studies 
reveal that some elderly say they know how to prevent it, but many of these associate prevention with poor eating habits, the use of alcohol or poor sanitary practices. Other women associate prevention with smoking, the number of partners, infections or inflammation of the uterus. A study conducted in Piauí state, in Northeastern Brazil, demonstrated the seniors` lack of knowledge about the Pap test, in contrast to the present study, which found that $90 \%$ were aware of the screening test [23]. This significant finding may be related to the characteristics of the participants, who belong to a social group, are all active, have access to information on health, and are encouraged to engage in physical activities, as well as enroll in handcraft, theater and choir classes. In relation to where they received information and encouragement regarding cervical cancer prevention, health professionals and screening campaigns predominated. By contrast, other studies reports that information is obtained from friends or family members who had or have the disorder and, and after that these people had the opportunity of read or heard about this issue [24]. Another study found that the elderly received information and encouragement from their doctors to undergo the Pap test, supporting the data obtained here [25]. In this study, elderly women were only aware of some of the risk factors for cervical cancer, reinforing literature findings that health professionals should be better equipped to deal with this population. As such, information campaigns on the risk factors and preventive measures for cervical cancer need to be intensified. It is vital that health professionals encourage patients to become involved in self-care and that information be made more available, given its importance for woman's health. In relation to the knowledge of seniors regarding HPV, this study demonstrated that most are aware of what it means. However, the literature shows an extreme absence of knowledge regarding HPV, resulting in a lack of concern and care on the part of women in relation to their health, primarily in terms of cervical cancer prevention. A significant number of respondents expressed interest in receiving information on cervical cancer, predominantly via lectures, talks and meetings. Few of the participants preferred written information such as pamphlets and flyers. Given its epidemiological importance in Brazil and the fact that cervical cancer is one of the most serious public health problems, funds have been allocated to preventive measures, which include both educational initiatives and practical steps such as providing the Pap test itself. However, gaps remain in terms of access to preventive programs [26]. When tests were applied to determine the association between sociodemographic factors and those related to prevention, a significant relation was found between age range and an active sex life. This association corroborates a study in which seniors reported no longer feeling the need for sex, or even thinking about having sexual relations. Myths are significant factors that lead women to believe they no longer need sex and have fulfilled that their "female obligations", thereby abandoning their sexuality [27]. Another study found that both elderly men and women continue to enjoy sexual relations, but that physiological changes may compromise sexual pleasure. To 
avoid this situation, individuals need to adapt to the changes that occur at this stage of life.

Two additional associations were found, namely between the number of children and undergoing preventive screening, and between the number of children and the use of contraception. More women with children undergo screening and use contraception than their childless counterparts. Studies demonstrate that, in addition to the infections caused by HPV, other factors related to the emergence of the disease include immunity, genetic causes, sexual behavior, multiparity, a large number of sexual partners, and early sexual activity. Women who attended health services more regularly for prenatal care obtained more information and, in turn, better care, in terms of screening and the means to protect themselves against sexually transmitted diseases such as HPV.

Two further associations with other factors were observed. Family income was associated with undergoing screening and an active sex life. The higher the family income, the more access to health services and information. The variation in access to cancer diagnosis and treatment, along with the quality of care, contribute to widening the disparities found in the mortality coefficients of the elderly female population in Brazil.

\section{Conclusions}

The present study demonstrated that most of the elderly interviewed were knowledgeable about cervical cancer and adopted preventive measures, but a number of gaps were observed with respect to preventive practices and knowledge.

As such, there is a need for more screening campaigns for the elderly focusing on the importance of preventive examinations, in order to diagnose suggestive or precursor lesions of cervical cancer and thereby detect tumors in the initial stages.

It is essential that seniors adopt preventive practices, such as an annual Pap test, in line with Ministry of Health Recommendations, since the number of cervical cancer cases has been increasing in this age group. In the coming decades, Brazil will have a substantial elderly population, making educational campaigns that encourage self-care and prevention extremely important.

\section{References}

[1] World Health Organization. Globocan 2012: Estimated Cancer Incidence, Mortality and Prevalence Worldwide in 2012. http://globocan.iarc.fr/Pages/online.aspx

[2] National Cancer Institute. Estimate 2016: Incidence of Cancer in Brazil. 2016a. Rio de Janeiro, RJ.

http://www.inca.gov.br/bvscontrolecancer/publicacoes/edicao/Estimativa_2016.pdf

[3] National Cancer Institute. Atlas of Mortality. 2016b. Rio de Janeiro, RJ. https://mortalidade.inca.gov.br/MortalidadeWeb/

[4] World Health Organization, ICO Information Centre on Human Papilloma Virus (HPV) and Cervical Cancer. Human Papillomavirus and Related Cancers in Brazil. 
Summary Report, 2014. https://www.who.int/hpvcentre

[5] Maeda, T.C., Alves, A.P. and Silva, S.R. (2012) Knowledge of Elderly Women on the Pap Smear. Science, Care and Health, Maringá/PR, 11, 360-367.

[6] Freitas, M.C.M. (2012) Determinants of Access to Pap Smear by Elderly Women in the City of Juiz de Fora/MG. Dissertation, Federal University of Juiz de Fora, Juiz de Fora.

[7] Triola, M.F. (2001) Elementary Statistics Using Excel. Addison and Wesley, NY.

[8] Araújo, et al. (2014) Prevention of Cervical Cancer in the View of the Nurse of the Basic Health Unit. Web Magazine of UNIVAR, Vale do Araguaia/MT, 1, 170-175.

[9] Eriksen, M., Mackay, J. and Ross, H. The Tobacco Atlas. http://www.tobaccoatlas.org/

[10] They Communicated DM. Perceptions and Attitudes of Women Regarding the Prevention of Cervical Cancer. 2012. 47 f. [Specialization]. [Counselor Lafaiete]. Federal University of Minas Gerais/MG, 2012.

[11] Fonseca, W., Godoi, S.D.C. and Silva, J.V.B. (2010) Papanicolau in the Elderly: Knowledge and Attitude of the Elderly Enrolled in a Strategy of Family Health in the City of Itaporã/MS. Revista Brasileira de Ciências do Envelhecimento Humano, 7, 357-369.

[12] Silva, J.C. (2003) Old or Seniors? The Third Age (SESC/SP), 14, 94-111.

[13] Olhê, L., et al. (2013) Papanicolau in the Elderly: A Challenge for Nursing. Magazine Fafibe, 6, 78-86.

[14] Santos, M.S., et al. (2011) Knowledge and Practices of Elderly Women in the Prevention of Cervical-Uterine Cancer. Brazilian Journal of Nursing, 3, 465-471.

[15] Floriano, M.I., Araújo, C.S.A. and Ribeiro, M.A. (2007) Knowledge about Risk Factors Associated with Cervical Cancer in the Elderly in Umuarama/PR. Arquivos de Ciências da Saúde da UNIPAR, 15, 199-203.

[16] Ministry of Health. Information System for Cervical Cancer and Information System for Breast Cancer. http://w3.datasus.gov.br/siscam/index.php?area=0401

[17] Azevedo, J.R.D. (1998) Staying Young Takes Time: Sexuality. Saraiva, São Paulo, 200.

[18] Reis, M.M.F. Female Aging and Sexuality. http://www.instituto-h-ellis.com.br/unidade_freicaneca/textos

[19] Malta, E.F.G.D. (2014) Factors Related to the Inadequate Practice of the Pap Smear by Women from the Interior of Ceará. Dissertation, Federal University of Ceará, Fortaleza.

[20] Silva, S.R., Silveira, C.F. and Gregório, C.C.M. (2012) Reasons Alleged for Not Performing the Pap Smear, According to Women in Chemotherapy Treatment against Cervical Cancer. Revista Mineira de Enfermagem, 16, 579-587.

[21] Maschio, M.B.M., et al. (2011) Sexuality in the Elderly: Prevention Measures for Sexually Transmitted Diseases and AIDS. Revista Gaúcha de Enfermagem, 32, 583589. https://doi.org/10.1590/S1983-14472011000300021

[22] Silva, M.S., et al. (2011) Knowledge and Practices of Elderly Women in the Prevention of Cervical-Uterine Cancer. Revista Brasileira de Enfermagem, 64, 465-471.

[23] Pinheiro, D.M., et al. (2013) Prevention of Cervical Cancer in Long-Term Institutions for the Elderly. Revista de Enfermagem da UFPI, 2, 27-32.

[24] Santos, R.F.A., et al. (2015) Knowledge of the Elderly on Cytopathological Examina- 
tion. Revista de Enfermagem UFPE, 9, 517-525.

[25] Crespi, T.D., et al. (2014) Relation between the Degree of Fragility of the Elderly and the Performance of Preventive Examinations. Revista Brasileira de Ciências do Envelhecimento Humano, 11, 276-287.

[26] Duque, K.C.D. (2013) Prevention of Cervical Cancer in an Area Covered by the Family Health Strategy. Dissertation, Federal University of Juiz de Fora/MG, Juiz de Fora.

[27] Costa, R.B., et al. (2015) Sexuality in Elderly Participants of a Coexistence Group. Health and Research Journal, 8, 239-245. 